None declared, E. Brouwer Consultant for: Roche, M. Cid Speakers bureau: Roche, Novartis, B. Dasgupta Speakers bureau: Roche, GlaxoSmithKline, J. Rech: None declared, C. Salvarani: None declared, G. Schett Speakers bureau: AbbVie, Bristol-Myers Squibb, Celgene, Chugai, GlaxoSmithKline, Lilly, Novartis, Roche, Sanofi, UCB, H. Schulze-Koops: None declared, R. Spiera Grant/research support from: Roche, Genentech, Consultant for: Roche, Genentech, S. Unizony: None declared, N. Collinson Employee of: Roche Products Ltd. DOI: 10.1136/annrheumdis-2017-eular.2381

\section{OP0132 LOW-DOSE INTERLEUKIN-2 SELECTIVELY RESTORE REGULATORY T CELL NUMBERS IN PATIENTS WITH BEHCET'S DISEASE}

X. Fu ${ }^{1}, \mathrm{~J}^{\mathrm{Li}}{ }^{2}, \mathrm{X} . \mathrm{Li}^{2}, \mathrm{~J} . \mathrm{Luo}^{2}, \mathrm{C} . \mathrm{Gao}^{2}$, Q. Chen ${ }^{2} .{ }^{1}$ Department of Rheumatism; ${ }^{2}$ The Second Hospital of Shanxi Medical University, Taiyuan, China

Background: The lack of $\mathrm{CD} 4^{+} \mathrm{CD} 25^{+} \mathrm{Foxp}^{+} \mathrm{T}$ regulatory cell (Treg) has been associated with human systemic autoimmune diseases, such as Behcet's disease (BD). IL-2, an essential growth and survival factor for Treg cells. However, the significance of Treg cells in the pathogenesis and the effect of low dose of IL-2 on $\mathrm{BD}$ are remain to investigate.

Objectives: The lack of $\mathrm{CD} 4^{+} \mathrm{CD} 25^{+} \mathrm{Foxp}^{+}{ }^{+} \mathrm{T}$ regulatory cell (Treg) has been associated with human systemic autoimmune diseases, such as Behcet's disease (BD). IL-2, an essential growth and survival factor for Treg cells. However, the significance of Treg cells in the pathogenesis and the effect of low dose of IL-2 on $\mathrm{BD}$ are remain to investigate.

Methods: Eighty patients with $\mathrm{BD}$ and seventy healthy donors were enrolled. $\mathrm{CD} 4^{+} \mathrm{T}$ cell subsets in peripheral blood mononuclear cells from these people were measured by multicolour flow cytometry. Twenty-six patients were treated daily with subcutaneous injections of 0.5 million IU of human IL-2 for five consecutive days, $\mathrm{CD} 4^{+} \mathrm{T}$ cell subsets were analysed before and after treatment by flow cytometry. Results: Compared to health control,the absolute counts of circulating Treg cells were significantanty decreased in patients with BD (median:29.93 cell/uL VS median:33.16 cell/uL; $p=0.039$ ) and it is negative correlation with disease activity. While the ratios of Th17/Treg in patients with BD (median:0.29;n=80,p=0.034) were significantly higher than those of health control (median:0.2;n=70). No diffrernce in the absolute counts of circulating Th17 cells $\left(\mathrm{CD} 4^{+} \mathrm{IL}-17^{+}\right)$between patients with $\mathrm{BD}$ and health control. Treatment of patients with $\mathrm{BD}$ with a low-dose of IL-2 regimen selectively increased the absolute counts of Treg cells, from a median of $18.97 \mathrm{cell} / \mathrm{uL}$ to $74.68 \mathrm{cell} / \mathrm{uL}$ (at 5 days) $(\mathrm{p}=0.000)$. No significant difference was observed in the absolute counts of circulating Th17, Th1 and Th2 cells after IL-2 treatment.

Conclusions: Th17/Treg cells may play a role in the pathogenesis of Patients with BD, low-dose of IL-2 proposes a selective biological treatment strategy by restoring immune tolerance.

Disclosure of Interest: None declared

DOI: 10.1136/annrheumdis-2017-eular.4047

\section{OP0133 COLOUR DOPPLER ULTRASONOGRAPHY OF FACIAL AND OCCIPITAL ARTERIES IN PATIENTS WITH GIANT CELL ARTERITIS: THE FREQUENCY OF INVOLVEMENT AND THE ROLE OF THEIR ASSESSMENT IN DAILY PRACTICE: A PROSPECTIVE STUDY}

$\underline{\text { R. Jese, }}$ Ž. Rotar, M. Tomšič, A. Hočevar. Department of Rheumatology, University Medical Centre Ljubljana, Ljubljana, Slovenia

Background: Giant cell arteritis (GCA) is the most common systemic large and medium size artery vasculitis in Western countries. Colour Doppler Sonography (CDS) allows us to study the involvement of the cranial arteries other than the temporal arteries in GCA which cannot be safely biopsied such as the facial $(\mathrm{FaA})$, and occipital (OcA) arteries.

Objectives: We aimed to estimate the frequency of the FaA, and OcA involvement in GCA; and to explore the clinical characteristics of these subgroups of patients. Methods: From 1 January 2014 to 31 December 2016, we prospectively performed a CDS of the FaA, and OcA in addition to the temporal (TA), and the extracranial supra-aortic arteries in all newly diagnosed patients suspected of having GCA. We used a Philips IU22 with a $5-17.5 \mathrm{MHz}$ multi-frequency linear probe from January 2014 to August 2016 and a Philips Epiq 7 with a 5-18 MHz multi-frequency linear probe from September 2016 to December 2016. All the arteries were evaluated in two planes for the highly specific halo-sign.

Results: During the 36-month observation period we performed a CDS of the cranial and extra-cranial arteries in 93 GCA ( $66.7 \%$ female) patients. The patients' median (IQR) age was 73.7 (66.1-79.1) years, and they had a median (IQR) symptom duration of $30(21-90)$ days. We observed the halo-sign on the FaA, and OcA in $38(40.9 \%)$, and $29(31.2 \%)$ cases, respectively. The FaA, and OcA were simultaneously affected in $18 / 93(19.4 \%)$ cases. The FaA, or OcA were affected in 4/22 (18.2\%) patients with a negative TA CDS. Patients with an $\mathrm{FaA}$ involvement had the highest frequency of severe visual manifestations, with permanent visual loss representing $70 \%$ of all visual manifestations. Patients with an OcA involvement least commonly had extracranial large vessel disease. Conclusions: A fifth of patients with a negative CDS of the TAs had signs of vasculitis only on the CDS of the FaA, or OcA. The CDS of the FaA, and OcA identified approximately 5\% more patients with GCA than the CDS of the TA alone.

Disclosure of Interest: None declared

DOI: 10.1136/annrheumdis-2017-eular.6073

\section{OP0134 LONG TERM OUTCOME AND PROGNOSIS FACTORS OF COMPLICATIONS IN TAKAYASU'S ARTERITIS: MULTICENTER STUDY OF 318 PATIENTS}

C. Comarmond $^{1}$, L. Biard ${ }^{2}$, M. Lambert ${ }^{3}$, A. Mekinian ${ }^{4}$, Y. Ferfar ${ }^{1}$, J.-E. Kahn ${ }^{5}$ Y. Benhamou ${ }^{6}$, L. Chiche ${ }^{7}$, F. Koskas ${ }^{7}$, P. Cluzel ${ }^{8}$, E. Hachulla ${ }^{3}$, E. Messas ${ }^{9}$, M. Resche-Rigon ${ }^{10}$, T. Mirault ${ }^{9}$, P. Cacoub ${ }^{1}$, D. Saadoun ${ }^{1}$ on behalf of French Takayasu network. ${ }^{1}$ Internal Medicine and Clinical Immunology, GROUPE HOSPITALIER PITIÉ-SALPÊTRIĖRE; ${ }^{2}$ Saint-Louis, Paris; ${ }^{3}$ Internal Medicine, CHU Lille, Lille; ${ }^{4}$ Internal Medicine, CHU Saint-Antoine, Paris; ${ }^{5}$ Internal Medicine, Foch, Suresnes; ${ }^{6}$ Internal Medicine, CHU Rouen, Rouen; ${ }^{7}$ Vascular surgery; ${ }^{8}$ Imagerie CardioVasculaire et de Radiologie Interventionnelle, GROUPE HOSPITALIER PITIÉ-SALPÊTRIËRE; ${ }^{9}$ Vascular Medicine, HEGP;

${ }^{10}$ SBIM, Saint-Louis, Paris, France

Objectives: To assess long term outcome and to elaborate a prognostic score for vascular complications in patients with Takayasu arteritis (TA).

Methods: Retrospective multicenter study of characteristics and outcome of 318 TA patients [86\% of females; median age 36 [25-47] years; median follow-up of 6.1 years] fulfilling ACR and/or Ishikawa criteria. Factors associated with the event free survival (EFS), relapse free survival (RFS) and incidence of vascular complications were assessed. A prognostic score for vascular complications was elaborated based on a multivariate model.

Results: The 5- and 10-years event free survival (EFS), relapse free survival (RFS) and complication free survival were $48.2 \%(42.2 ; 54.9)$ and $36.4 \%$ (30.3;43.9), $58.6 \%(52.7 ; 65.1)$ and $47.7 \%(41.2 ; 55.1)$, and $69.9 \%(64.3 ; 76)$ and $53.7 \%(46.8 ; 61.7)$, respectively. Progressive disease course $(p=0.018)$ and carotidodynia $(\mathrm{p}=0.036)$ were independently associated with EFS. Male gender $(p=0.048)$, elevated $C$ reactive protein level $(p=0.013)$, and carotidodynia $(p=0.003)$ were associated with RFS. Progressive disease course $(p=0.017)$, thoracic aorta involvement $(p=0.009)$, and retinopathy $(p=0.002)$ were associated with complication free survival. We define high risk patients for vascular complications according to the presence of two of the following factors (i.e a progressive clinical course, thoracic aorta involvement and/or retinopathy). The probability of complication free survival at five years was $78.4 \%(69.4 ; 88.6)$ and $51.5 \%(38.3 ; 69.2)$ in the low risk and high risk group, respectively.

Conclusions: This nationwide study shows that $50 \%$ of TA patients will relapse and experience a vascular complication at 10 years. We could define high risk TA patients for vascular complications.

Disclosure of Interest: None declared

DOI: 10.1136/annrheumdis-2017-eular.3579

\section{OP0135 TOCILIZUMAB IN GIANT CELL ARTERITIS: GIACTA TRIAL VERSUS A SERIES OF PATIENTS FROM CLINICAL PRACTISE}

L.C. Domínguez-Casas ${ }^{1}$, J. Loricera ${ }^{1}$, A. Mera ${ }^{2}$, E. Pérez-Pampín ${ }^{2}$, J.L. Hernández ${ }^{3}$, S. Castañeda ${ }^{4}$, N. Vegas-Revenga ${ }^{1}$, E. Pons ${ }^{1}$, M.Á. González-Gay ${ }^{1}, R$. Blanco ${ }^{1} .{ }^{1}$ Rheumatology, Hospital Universitario Marqués de Valdecilla. IDIVAL, Santander; ${ }^{2}$ Rheumatology, Complejo Hospitalario Universitario de Santiago, Santiago de Compostela; ${ }^{3}$ Internal Medicine, Hospital Universitario Marqués de Valdecilla. IDIVAL, Santander; ${ }^{4}$ Rheumatology, Hospital Universitario de la Princesa, Madrid, Spain

Background: Baseline characteristics of patients from GiACTA trial have been recently reported at the ACR-2016 conference (1). GiACTA trial is a randomized, phase III controlled clinical trial evaluating the efficacy of tocilizumab (TCZ) in giant cell arteritis (GCA) (2). We had previously published a multicenter study on the use of TCZ in refractory GCA in a clinical practice setting (3).

Objectives: Our aim was to compare both studies, emphasizing on the baseline characteristics of the patients.

Methods: Comparative study between the GiACTA trial and our multicenter clinical practice study. In the latter, the diagnosis of GCA was established by the ACR-1990 criteria and in the GiACTA trial by the ACR modified criteria. In the clinical practice study, TCZ was used at standard IV dose $(8 \mathrm{mg} / \mathrm{kg} / \mathrm{month})$, while in the GiACTA trial it was given subcutaneously ( $162 \mathrm{mg}$ every 1 or 2 weeks, depending on the therapeutic arm). Quantitative variables were expressed as mean \pm SD and were compared with the Student's t-test. Dichotomous variables were expressed as percentages and compared using the chi-square test.

Results: In the GiACTA trial, $47.4 \%$ were newly diagnosed GCAs, while in the clinical practice study were all refractory to conventional treatment. The TABLE summarizes the main baseline characteristics of both studies. Compared with the GiACTA trial, in the clinical practice study were significantly greater: a) the mean time between the diagnosis of GCA and the onset of TCZ, b) the proportion of patients with polymyalgia rheumatica and ischemic optic neuritis, c) the proportion of positive PET/CT scans, d) the mean value of ESR, and e) the proportion of patients who had received conventional immunosuppressant agents (mainly MTX) before starting TCZ. There was also a significant lower proportion of sustained remission in the clinical practice study. When only GiACTA patients with 
relapsing-GCA were analyzed, these differences were maintained, except for the mean time from GCA diagnosis and the prevalence of ischemic optic neuropathy. Data on remissions were not available in this subgroup of GiACTA patients.

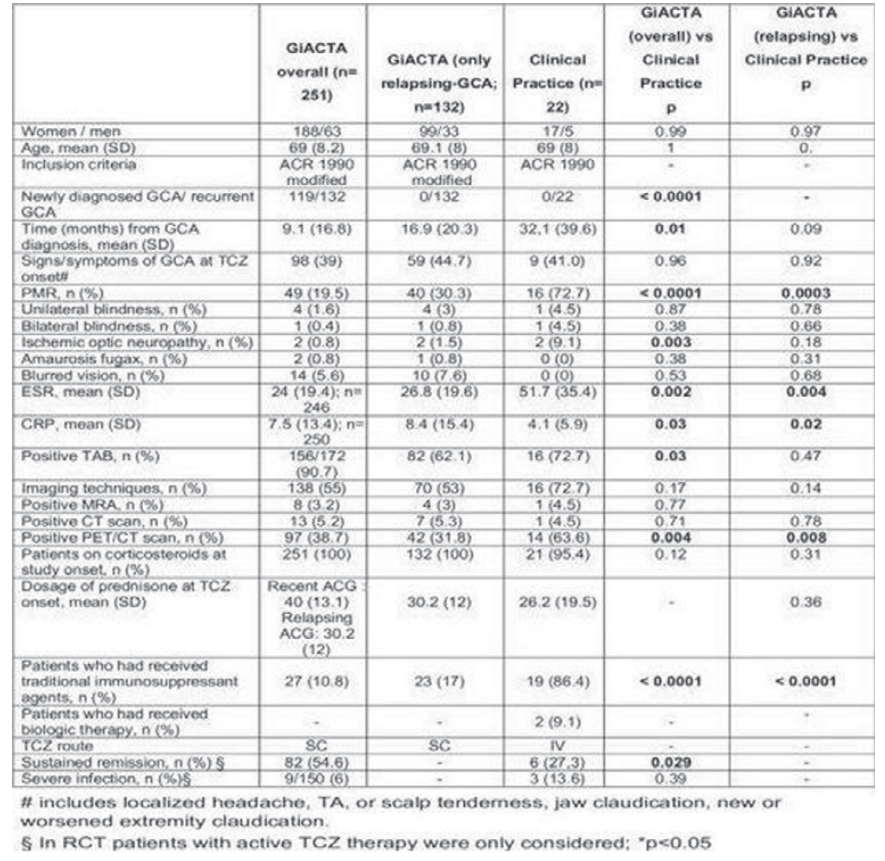

Conclusions: Patients receiving TCZ in the clinical practice study have several baseline clinical and laboratory differences with regard to those included in the GiACTA trial and, therefore, data of this trial should be taken cautiously when applied in a real-world scenario.

References:

[1] Stone J et al. Arthritis Rheumatol.2016; 68 (suppl 10). http://acrabstracts.org/ abstract/efficacy-and-safety-of-tocilizumab-in-patients-with-giant-cell-arteritisprimary-and-secondary-outcomes-from-a-phase-3-randomized-double-blindplacebo-controlled-trial/.

[2] Tuckwell K et al. Semin Arthritis Rheum. 2016 Nov 15. pii: S00490172(16)30275-X

[3] Loricera J et al. Semin Arthritis Rheum. 2015; 44: 717-23.

Disclosure of Interest: None declared

DOI: 10.1136/annrheumdis-2017-eular.3489

\section{OP0136 MICRORNA-223-3P EXPRESSION IN AFFECTED SKIN OF ADULT IGA VASCULITIS CORRELATES WITH THE SEVERITY OF SKIN INVOLVEMENT}

A. Hocevar ${ }^{1}$, J. Pizem ${ }^{2}$, M. Tomsic ${ }^{1}$, D. Glavac ${ }^{2} .{ }^{1}$ Department of Rheumatology, University Medical Centre Ljubljana; ${ }^{2}$ Institute of Pathology, Faculty of Medicine, University of Ljubljana, Ljubljana, Slovenia

Background: IgA vasculitis (IgAV) represents a common systemic vasculitis in paediatric and adult population. Our current knowledge of disease pathogenesis is still very limited and there is no information on miRNAs profile in IgAV.

Objectives: The aim of our study was to determine the expression of three miRNAs (miR-148-3p, miR-155-5p and miR-223-3p) in the affected skin of adult IgAV patients.

Methods: The study included 65 skin samples from consecutive, untreated IgAV patients $(61 \%$ male, median age 67.6 years, range 29-91), diagnosed between October 2014 and September 2016, and 10 control skin samples. Total RNA was isolated from tissue section of formalin-fixed, paraffin-embedded samples of biopsied IgAV vasculitic skin lesions and normal skin samples. Expression of miR-148-3p, miR-155-5p and miR-223-3p was measured using qRT-PCR. Skin miRNAs expression was then correlated to clinical characteristics of adult IgAV patients. To present relative miRNA expression the $\triangle \Delta$ CT method was used. Results: We found significantly higher expression levels of miR-223-3p in the affected skin compared to controls (14-fold; $p<0.001$ ). The expression of the 148b$3 p$ and miR-155-5p was near normal levels (1.05-fold and 1.13-fold increase, respectively). The differences in the expression of miR-223-3p depending on clinical parameters of IgAV are presented in Table 1. Patients with necrotic skin lesions had significantly higher miR-223 tissue expression than those with non-necrotic purpura $(p=0.020)$. Gastrointestinal tract $(G I T)$ involvement inversely correlated with the level of skin miR-223 expression $(p=0.024)$. No significant relationship between renal involvement and skin miR-223 was found.

Conclusions: miR-223 expression was increased in the affected skin of IgAV in comparison to normal skin. Levels of miR-223 expression correlated with severity of skin involvement and inversely with GIT involvement.
Table 1. miR-223-3p expression in IgAV

\begin{tabular}{|c|c|c|c|c|c|c|}
\hline \multirow[t]{2}{*}{ Characteristics } & & \multirow[t]{2}{*}{ Number of cases } & \multicolumn{3}{|c|}{$\Delta \Delta C T$ miR223-3p } & \multirow[t]{2}{*}{$P$ value } \\
\hline & & & median & IQR1 & IQR2 & \\
\hline \multirow[t]{2}{*}{ General symptoms } & YES & 10 & 3.11 & 1.86 & 5.55 & 0.683 \\
\hline & NO & 55 & 3.72 & 2.53 & 5.38 & \\
\hline \multirow[t]{2}{*}{ Arthritis } & YES & 6 & 3.04 & 2.67 & 4.60 & 0.482 \\
\hline & NO & 59 & 3.72 & 2.48 & 4.60 & \\
\hline \multirow[t]{2}{*}{ Generalized purpura } & YES & 37 & 3.72 & 2.46 & 5.87 & 0.615 \\
\hline & NO & 28 & 3.63 & 2.56 & 5.10 & \\
\hline \multirow[t]{2}{*}{ Skin necroses } & YES & 32 & 4.68 & 2.94 & 5.84 & 0.020 \\
\hline & NO & 33 & 3.19 & 1.97 & 4.76 & \\
\hline \multirow[t]{2}{*}{ GIT involvement } & YES & 16 & 2.78 & 1.69 & 3.90 & 0.024 \\
\hline & NO & 49 & 4.29 & 2.69 & 5.62 & \\
\hline \multirow[t]{2}{*}{ Severe GIT involvement } & YES & 5 & 2.67 & 1.88 & 3.07 & 0.078 \\
\hline & NO & 60 & 4.22 & 2.56 & 5.57 & \\
\hline \multirow[t]{2}{*}{ Renal involvement } & YES & 28 & 4.29 & 2.69 & 5.72 & 0.260 \\
\hline & NO & 37 & 3.20 & 1.82 & 5.41 & \\
\hline \multirow[t]{2}{*}{ Severe renal involvement } & YES & 9 & 4.50 & 2.44 & 5.13 & 0.955 \\
\hline & NO & 56 & 3.60 & 2.49 & 5.50 & \\
\hline \multirow[t]{2}{*}{ Elevated serum IgA level } & YES & 30 & 4.63 & 2.71 & 5.93 & 0.041 \\
\hline & NO & 35 & 3.19 & 1.75 & 4.80 & \\
\hline
\end{tabular}

Legend: generalized purpura - purpura above the waist; GIT - gastrointestinal tract; severe GIT involvement - bloody diarrhoea or ileus or surgical intervention; severe renal involvement - acute kidney injury or nephrotic syndrome.

Disclosure of Interest: None declared

DOI: 10.1136/annrheumdis-2017-eular.2250

\section{OP0137 AUTO-REACTIVE B CELLS ESCAPE PERIPHERAL TOLERANCE CHECKPOINTS IN PATIENTS WITH PR3-ANCA ASSOCIATED VASCULITIS}

$\underline{D . ~ C o r n e c ~}^{1,2}$, A. Hummel ${ }^{1}$, T. Peikert ${ }^{1}$, J.-O. Pers ${ }^{2}$, U. Specks ${ }^{1}$. ${ }^{1}$ Mayo Clinic, Rochester MN, United States; ${ }^{2} \mathrm{CHRU}$ and University, Brest, France

Background: While extensive studies have been performed to characterize ANCA, little is known about the auto-reactive B cells that produce these autoantibodies. Indirect evidence previously suggested the presence of circulating PR3-specific B cells in patients with PR3-ANCA-associated vasculitis (AAV).

Objectives: To develop a method to detect circulating PR3-specific B cells in patients with PR3-AAV, to study their proportion among the different B-cell subsets and to assess their relationship with disease activity.

Methods: An enzymatically inactive, conformationally mature, recombinant PR3 (rPR3) was tagged using FITC or biotin. To study the ability of this rPR3 to bind specifically to cells expressing PR3-specific immunoglobulins on their surface, we used two hybridoma cell lines, MCPR3-2 (producing an anti-human PR3 monoclonal antibody) and MCPR3-13 (producing an anti-mouse PR3 monoclonal antibody, with no cross-reactivity with human PR3). We measured the proportion of PR3-FITC positive B cells among PBMCs in 13 patients with PR3-AAV and 14 healthy controls (HCs) by flow cytometry. We then developed a multi-color flow cytometry including CD19, IgD, CD27, CD38, CD24 and biotinylated rPR3 to measure the proportion of PR3-specific B cells among different B-cell subsets in an independent group of 13 patients with PR3-AAV and $11 \mathrm{HCs}$.

Results: rPR3 efficiently bound MCPR3-2 hybridoma cells but not MCPR3-13. Specificity of the staining was confirmed by competition experiments: preincubation of MCPR3-2 cells with untagged human rPR3 totally abrogated rPR3-FITC staining, whereas pre-incubation with mouse rPR3 had no effect. Dose-ranging experiments defined the optimal concentration of rPR3 to stain cells expressing anti-PR3 immunoglobulin. The mean (SEM) proportion of rPR3-FITC stained B cells was higher in patients with PR3-AAV compared to HCs: $2.10 \%$ (2.33) vs $0.45 \%(0.19)$ respectively, $\mathrm{p}<0.001$. Patients with active disease had numerically higher proportions of PR3-specific $B$ cells than patients in remission: $3.66 \%(3.28)$ vs $1.10 \%(0.52), p=0.09$. In HCs, the proportion of PR3-specific $\mathrm{B}$ cells was highest among the transitional B-cell subset, and decreased along with the maturation of $B$ cells (figure). Conversely, in patients, the proportion of PR3-specific B cells progressively increased with the maturation of B cells (median $1.9 \%$ of naïve B cells, $2.30 \%$ of IgD+ memory B cells, $2.37 \%$ of IgDmemory $\mathrm{B}$ cells, and $3.68 \%$ of plasmablasts, $\mathrm{p}<0.05$ for all comparisons with the naïve subset).
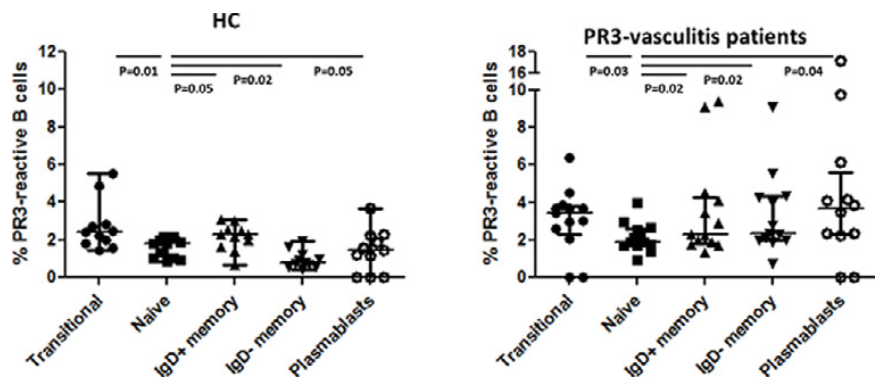

Conclusions: This study describes an original method to detect and study 